\title{
Desain Trivia Game untuk Latihan Assessment Kompetensi Minimum Tradisional pada Matematika Kelas V SD
}

\author{
Diny Syarifah Sany ${ }^{1}$, Anisa Nurbaiti ${ }^{2}$ \\ Teknik informatika ${ }^{1}$, Pendidikan Matematika ${ }^{2}$, Universitas Suryakancana \\ dsy.sany@gmail.com ${ }^{1}$,nurbaitianisa37@gmail.com ${ }^{2}$
}

\begin{abstract}
The Indonesian government has made efforts to improve the quality of education, one of which is by holding a Minimum Competency Assessment (AKM) program. This AKM is a substitute for the school exam which consists of the traditional AKM and the alternative AKM. Traditional AKM focuses on student knowledge. The AKM practice questions are needed but the paper method that is currently being implemented is less effective given the reduction in direct meetings between students and teachers. A trivia game can be used for Education. However, there is no trivia game design that is compatible with traditional AKM practice questions, so this research focuses on making trivia game designs. The design is designed based on field studies and literature studies from previous research regarding what game mechanics are suitable to be applied to the AKM practice questions. Testing is done by implementing the design into a programming language and a questionnaire after trying the game. The results of this test show that the game produced from the proposed design can motivate, attract and have fun so that the proposed design can be used as a reference for making similar games.
\end{abstract}

Keywords: Assessment Kompetensi Minimum, game, serious game, trivia game, game design

\begin{abstract}
Abstrak
Pemerintah Indonesia telah berupaya untuk meningkatkan kualitas Pendidikan salah satunya dengan mengadakan program Assessment Kompetensi Minimum (AKM). AKM ini merupakan pengganti ujian sekolah yang terdiri dari AKM tradisional dan AKM alternatif. AKM tradisional berfokus kepada pengetahuan peserta didik. Latihan soal AKM diperlukan namun metode kertas yang sekarang dijalankan kurang efektif mengingat adanya pengurangan pertemuan langsung antara siswa dan guru. Trivia game dapat digunakan untuk Pendidikan. Namun belum ada desain trivia game yang sesuai dengan latihan soal AKM tradisional, sehingga penelitian ini berfokus pada pembuatan desain trivia game. Desain dirancang berdasarkan studi lapangan dan studi literatur dari penelitian sebelumnya mengenai game mekanik apa yang sesuai untuk diterapkan pada latihan soal AKM. Pengujian dilakukan dengan mengimplementasikan desain kedalam bahasa pemrograman dan kuisioner setelah mencoba permainan. Hasil dari pengujian ini didapat bahwa game yang dihasilkan dari desain yang diusulkan memiliki kemampuan memotivasi, menarik dan menyenangkan sehingga desain yang diusulkan dapat digunakan sebagai acuan untuk pembuatan game sejenis.
\end{abstract}

Kata kunci: Assessment Kompetensi Minimum, gim, gim serius, gim kuis, desain gim

\section{PENDAHULUAN}

Pendidikan merupakan faktor penting untuk memajukan sebuah negara. Pendidikan yang berkualitas menghasilkan masyarakat yang berkualitas pula. Pemerintah Indonesia telah mengupayakan berbagai hal untuk memberikan peningkatan terhadap kualitas Pendidikan, salah satunya dengan program Assessment Kompetensi Minimum (AKM). AKM mengukur proses belajar siswa yang dibagi menjadi tradisional dan dan alternatif [1]. AKM tradisional lebih kepada tes benar salah, pilihan ganda, soal melengkapi, tes jawaban terbatas atau tes yang bersifat menilai pengetahuan. Sedangkan AKM alternatif menilai pengembangan diri. Di Indonesia AKM memfokuskan kepada literasi membaca dan literasi numerasi. AKM yang dapat mengukur kemampuan mendasar peserta didik akan memberikan gambaran mengenai tingkat penguasaan kompetesi peserta $\operatorname{didik}[2]$.
Pandemi covid-19 memberikan dampak terhadap sekolah khususnya tingkat sekolah dasar. Di Indonesia, siswa yang biasanya belajar secara tatap muka kini mengalami keterbatasan dalam melakukan pembelajaran. Meskipun di tahun 2021 sudah mulai banyak yang bertatap muka namun tidak secara penuh. Di satu sisi, AKM merupakan hal yang penting namun ada sebuah batasan yang terjadi sehingga latihan soal yang biasanya dilakukan secara tatap muka oleh guru dan siswa menjadi sesuatu yang sulit dilakukan. Salah satu mata pelajaran yang tercantum dalam Permen sebagai matapelajaran AKM adalah Matematika. Matematika ini merupakan matapelajaran yang berfokus kepada pengetahuan numerasi.

Dalam perkembangannya gim bukan lagi menjadi sebuah hiburan semata namun dimanfaatkan diberbagai bidang seperti kesehatan, pendidikan, militer, dan sebagainya. Di dalam Pendidikan ada istilah edu-game. Game edukasi merupakan game yang mampu membantu 
siswa dalam mencapai tujuan pembelajarannya. Meskipun begitu prinsip belajar dan bermain game berbeda dan sering bertentangan, tetapi keduanya dapat hidup berdampingan jika dirancang dengan baik[3]. Sebuah penelitian menyatakan mengenai pengaruh game edukasi terhadap peningkatan pengetahuan, misalnya pada pembelajaran aljabar pada tingkat taman kanakkanak memberikan hasil yang signifikan[4].

Permainan Pendidikan dapat menggunakan berbagai genre seperti puzzle, platformer, trivia, simulasi, dan lain sebagainya. Permainan trivia atau kuis telah dimainkan begitu yang memungkinkan dibuat khusus untuk menguji pengetahuan pemain[5]. Beberapa penelitian mengemukakan mengenai trivia game diantaranya: trivia game memberikan kepuasan siswa terhadap lingkungan kelas, manajemen proses pembelajaran, dan guru[6], dapat mempromosikan wisata dan membuat pemain lebih mengenal dan memahami konten[7], pada pembelajaran music penerapan game trivia menghasilkan nilai diatas $80 \%$ [8], pada anak kelas 4 SD penerapan game kuis meningkatkan kemampuan siswa diperoleh skor total sebesar $87 \%$ yang divalidasi oleh ahli media, ahli materi dan ahli RPP[9], untuk kelas X dalam pelajaran fisika penerapan trivia game mampun meningkatkan prestasi siswa[10]. Dengan pengetahuan yang lebih dalam tentang nilai penyempurnaan game trivia, sejumlah tambahan game trivia dapat digunakan untuk menggeneralisasi nilai penyempurnaan game[5].

Latihan soal AKM sangat perlu untuk meningkatkan kualitas Pendidikan anak, namun belum ada desain rancangan permainan yang sesuai dengan latihan soal AKM, sehingga penelitian ini akan mengusulkan mengenai desain trivia game yang sesuai dengan soal AKM dengan studi kasus siswa kelas V SD. Desain yang diusulkan ini diharapkan mampu menjadi sebuah acuan untuk pengembang game saat akan membuat game sejenis.

\section{METODE PENELITIAN}

Metode penelitian pada penelitian ini terdiri dari pengumpulan data, perancangan, dan pengujian, yaitu:

a. Pengumpulan data dilakukan dengan 2 cara yaitu dengan studi lapangan dan studi literatur mengenai penelitian terkait.

b. Perancangan dilakukan dari hasil analisis data.

c. Pengujian dilakukan dengan mengimplementasikan desain ini menjadi sebuah permainan dan melakukan kuisioner terhadap siswa untuk melihat manfaat dari trivia game yang dibangun dengan menggunakan desain yang diusulkan.

Studi lapangan dilakukan untuk mengetahui kondisi atau kebutuhan apa yang diperlukan oleh anak kelas V SD. Hasil dari studi lapangan ini adalah desain konten dari game yang dibuat. Studi literatur dilakukan untuk mengumpulkan game mekanik apa saja yang sesuai untuk dapat dijadikan desain trivia game untuk latihan soal AKM Matematika dengan jenis AKM tradisional.

Pada proses perancangan, komponen-komponen yang ada dalam game atau game mekanik yang digunakan diambil dari LM-GM Framework[3]:

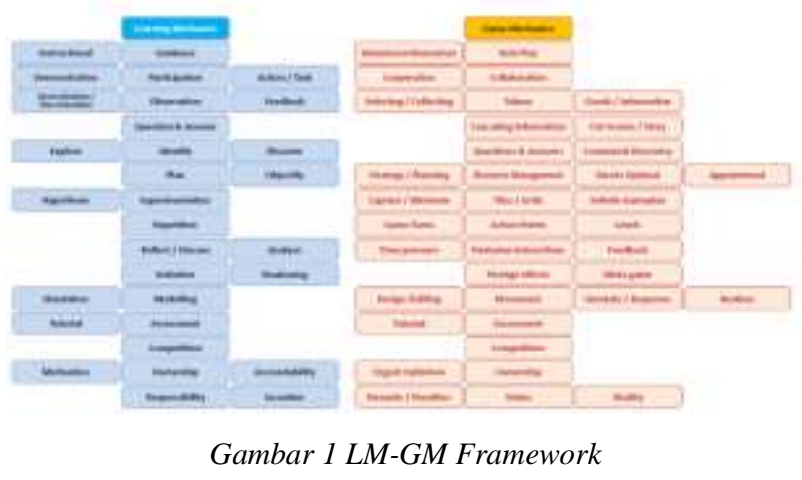

Dari LM-GM Framework ini diambil gim mekanik yang sesuai dengan AKM untuk matapelajaran Matematika. Sedangkan untuk taksonomi BLOOM yang ingin dicapai diambil dari klasifikasi LM-GM terhadap taksonomi BLOOM [3] berikut:

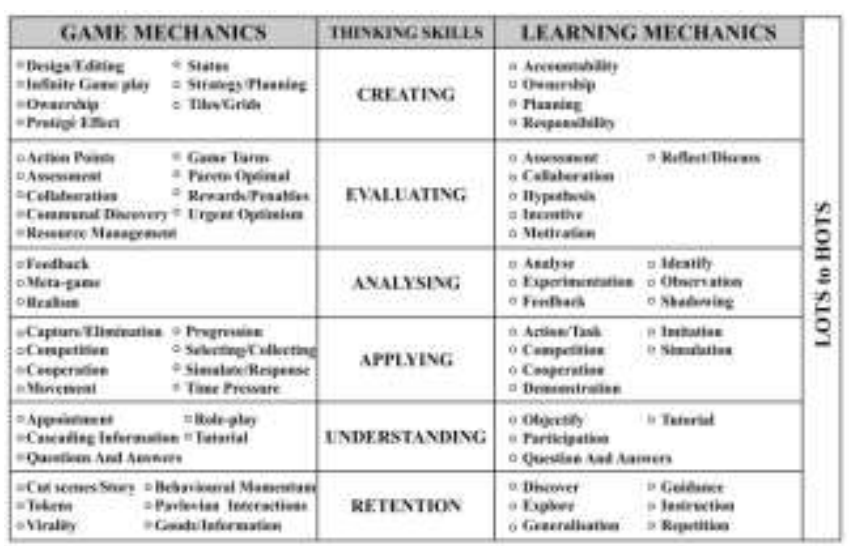

Gambar 2 klasifikasi LM-GM terhadap taksonomi BLOOM

Untuk latihan thinking skill yang diperlukan sampai pada tahap understanding. Sehingga komponen game mekanik yang diambil dan dijadikan desain merupakan game mekanik pada tahap thinking skill understanding.

\section{HASIL PENELITIAN}

Dari hasil studi lapangan, didapat bahwa latihan soal AKM yang dilakukan sekarang atau dengan metode kertas kurang efektif untuk anak sekolah dasar, sehingga latihan soal yang interaktif diperlukan untuk memotivasi para peserta didik dalam mengerjakan soal. Anak sekolah dasar juga menyukai warna atau tampilan yang menarik, tidak monoton, sehingga perlu adanya animasi tambahan untuk membuat tampilan lebih menarik sehingga peserta didik lebih semangat untuk mengerjakan soal latihan.

AKM untuk matapelajaran matematika terdiri dari tradisional dan alternatif. Trivia game dapat digunakan untuk latihan soal AKM tradisional. Untuk Trivia game ini jenis soal yang digunakan dapat berupa tes benar salah, pilihan ganda, soal melengkapi, tes jawaban terbatas. Untuk soal yang disajikan pada aplikasi harus sesuai dengan pertanyaan yang terdapat pada soal AKM. Soal ini dapat diambil dari soal tahun sebelumnya.

Mekanik gim yang digunakan sendiri untuk desain gim pada latihan soal AKM tradisional ini haruslah yang berfokus kepada sejauhmana pemahaman peserta didik terhadap materi pembelajaran. Karena fokus utama untuk 
melihat pemahaman maka mekanik permainan yang digunakan ada pada tahapan thinking skill understanding. Pada thinking skill understanding ini sendiri pada mekanik pembelajaran yang diberikan terdiri dari objectifity, participant, question and answer dan tutorial.

Objectifity merupakan sifat utama dari soal latihan AKM yang diberikan, bersifat objektif atau bukan berupa pendapat atau uraian Panjang berdasarkan pendapat peserta didik, sehingga memudahkan untuk melakukan penilaian sejauh mana pemahaman peserta didik dalam materi yang terdapat pada soal. Participant merupakan mekanik yang perlu juga dimana participant disini merupakan peserta didik. Pada question and answer ini merupakan komponen penting dalam target learning mechanic untuk latihan soal AKM dimana jenis ini dapat disesuaikan dengan kebutuhan namun tetap sesuai dengan jenis soal AKM tradisional, yaitu jawaban yang pasti. Untuk tutorial dapat diberikan untuk mengkoreksi jawaban peserta didik atau menjelaskan bagaimana cara mengerjakannya.

Untuk game mechanic yang digunakan adalah appointment, cascading information, tutorial, role play, dan question and answer. Sehingga desain yang diusulkan untuk soal AKM tradisional untuk pilihan ganda seperti berikut:

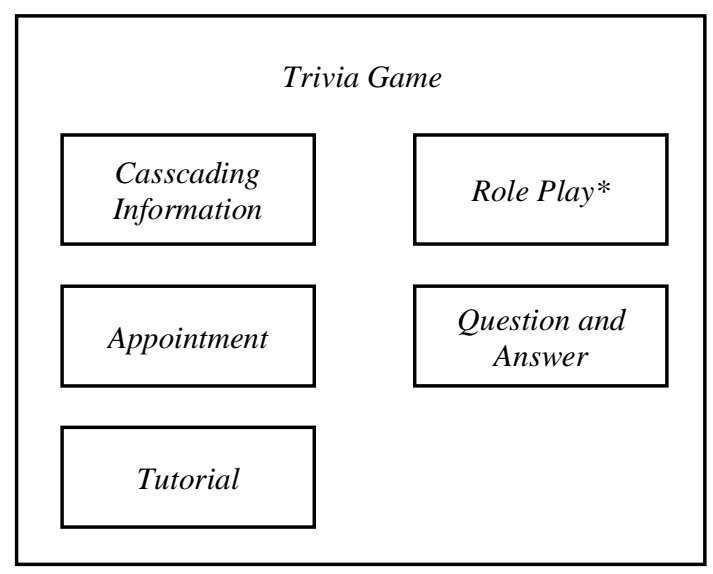

Gambar 3 Desain Trivia Game yang diusulkan untuk Soal AKM tradisional pilihan ganda

Ada 5 game mekanik yang diusulkan yaitu appointment, cascading information, role-play, tutorial, dan question and answer.

- Appointment, sifat dari mekanik ini yang diterapkan pada latihan soal AKM berupa penunjukkan jadi peserta didik tidak menjawab soal uraian namun memilih jawaban yang sudah tersedia.

- Casscading information, dapat digunakan untuk menampilkan informasi dasar pada game dengan menggunakan kotak informasi atau berupa soal yang ditampilkan, atau untuk menampilkan pembahasan soal latihan setelah mengerjakan. Pembahasan soal perlu dilakukan agar peserta didik dapat memahami bagian salah dari jawabannya.

- Tutorial, memiliki hubungan dengan cascading information dimana tutorial dapat ditampilkan secara cascading information namun dapat digarisbawahi bahwa tutorial disini bukan menampilkan pembelajaran hanya cara pengerjaannya atau pembahasan soal yang benar atau yang salah nya, karena fokus utama ada di penyelesaian soal AKM.

- Role play, merupakan sebuah genre tambahan memainkan peran, dalam Latihan soal AKM diberikan pilihan apakah akan ditambahkan permainan peran seperti seorang siswa yang sedang ujian, atau peran lainnya yang akhirnya merujuk kepada pengerjaan soal latihan AKM. Penambahan genre ini dapat menambah nilai menariknya game trivia ini.

- Question and answer disesuaikan dengan bentuk soal AKM yang dirancang oleh pemerintah seperti pertanyaan benar salah, pilihan ganda, melengkapi atau jawaban terbatas. Jawaban dari soal ini dibentuk untuk meghasilkan jawaban yang bukan berdasarkan pendapat namun jawaban yang hanya perlu dipilih oleh peserta didiknya.

Selain itu ada beberapa hal yang harus ada pada trivia game latihan soal AKM ini, yaitu:

- Menggunakan warna menarik sesuai dengan usia peserta didik

- Membuat tampilan mudah dipahami oleh peserta didik tidak menambahkan hal yang tidak perlu, focus pada pertanyaan jawaban dan skoring

- Pengoperasian yang mudah digunakan misal hanya menekan tombol saja (meminimalisir kontroler)

- Penambahan animasi diperbolehkan asal tidak berlebihan

- Pertanyaan dan jawaban mudah dibaca

- Adanya skoring setelah selesai melakukan latihan soal agar siswa dapat mengetahui nilai

- Adanya notifikasi mengenai jawaban mana yang tidak tepat sehingga peserta didik dapat mengevaluasi lebih lanjut

Untuk alur dari trivia game sendiri dapat didesain semenarik mungkin atau tidak ada aturan tertentu, namun berikut ini rekomendasi alur trivia game yang dapat digunakan sesuai dengan latihan soal AKM tradisional untuk soal numerasi atau matapelajaran matematika:

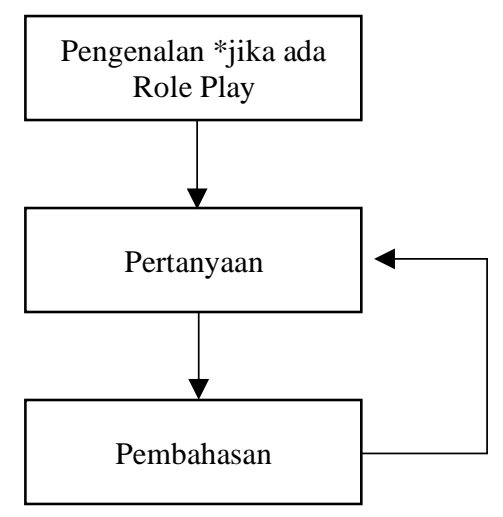

Gambar 4 rekomendasi alur game trivia game untuk game latihan soal AKM 
Jika trivia game yang dirancang melibatkan permainan peran maka harus dideskripsikan terlebih dahulu baik dengan menggunakan cerita atau perkenalan singkat diawal. Namun jika tidak menggunakan tidak perlu menggunakan cerita. Selanjutnya pertanyaan ditampilkan dan setelah itu menampilkan pembahasan. Sebaiknya pembahasan dilakukan setelah menjawab pertanyaan persatuan pertanyaan. Ini bertujuan agar peserta didik langsung dapat mengetahui kesalahan yang dilakukan olehnya disbanding jika harus menjawab semua soal terlebih dahulu lalu melakukan pembahasan. Tujuan latihan sendiri adalah untuk melatih pemahaman, mengkoreksi kesalahan pemahaman, sehingga dapat meningkatkan pengetahuan dari peserta didik itu sendiri. Alur ini dapat dilakukan secara berulang jadi setelah pembahasan dimunculkan kembali pertanyaan setelah menjawab ada koreksi dan pembahasan.

\section{PEMBAHASAN}

Untuk menguji desain yang diusulkan sesuai dengan tujuan dari latihan soal AKM atau tidak maka dibuat sebuah game trivia latihan soal AKM tradisional pilihan ganda untuk menguji kemampuan numerasi yaitu matapelajaran matematika untuk selanjutnya dapat diujikan kepada siswa kelas V SD. Siswa kelas V SD yang menjadi subjek uji adalah kelas V SD di desa Ramasari Kabupaten Cianjur. Berikut ini merupakan hasil implementasi:

\section{SOAL 1 - LEVELI}

$1,3,5,7,9, \ldots, 13$.

BILANGAN YANG TEPAT UNTUK DiISI PADA ... ADALAH

10

11

NiLAi:0

KEMBALI

Gambar 5 Antar muka latihan soal AKM

Permainan ini terdiri dari dua level, mudah dan sulit dimana soal-soal disesuaikan dengan soal AKM untuk kelas V SD. Setelah melakukan implementasi ini peserta didik yang menjadi subjek uji memainkan terlebih dahulu permainan ini setelah bermain lalu dilakukan kuisioner kepada setiap pemain, dengan jawaban ya/tidak disesuaikan dengan kapasitas siswa dalam menjawab soal kuisioner. Poin-poin yang ditanyakan dalam kuisioner ini adalah sebagai berikut:

- P1, apakah senang dengan latihan melalui gim

- P2, apakah suka dengan latihan melalui gim

- P3, apakah dapat meningkatkan kemampuan menjawab soal AKM matematika

- P4, apakah tampilan gim menarik

- P5, apakah teks mudah dipahami

- P6, apakah animasi membuat gim menarik

- P7, apakah latihan AKM dengan gim lebih menarik daripada latihan seperti biasa (dari buku tekstual)

- P8, apakah gim ini mendorong untuk semangat latihan AKM

- P9, apakah cara menjawab soal mudah dilakukan

- P10, apakah pemberian skor cukup menjelaskan seberapa pemahaman mengenai matematika

Pengujian ini dilakukan kepada siswa kelas V SD berjumlah 12 orang, dengan hasil sebagai berikut:

\begin{tabular}{|c|c|c|c|c|c|c|c|c|c|c|}
\hline \multirow{2}{*}{$\begin{array}{l}\text { Kores- } \\
\text { ponden }\end{array}$} & \multicolumn{10}{|c|}{ Pertanyaan } \\
\hline & $\mathrm{P} 1$ & $\mathrm{P} 2$ & P3 & $\mathrm{P} 4$ & P5 & P6 & $\mathrm{P} 7$ & P8 & $\mathrm{P} 9$ & $\mathrm{P} 10$ \\
\hline K1 & 1 & 1 & 1 & 2 & 1 & 2 & 1 & 1 & 1 & 1 \\
\hline $\mathrm{K} 2$ & 1 & 2 & 1 & 1 & 1 & 1 & 2 & 1 & 2 & 1 \\
\hline K3 & 1 & 1 & 1 & 1 & 1 & 1 & 1 & 2 & 1 & 2 \\
\hline K4 & 1 & 1 & 1 & 1 & 1 & 1 & 1 & 1 & 1 & 1 \\
\hline K5 & 1 & 1 & 1 & 1 & 1 & 1 & 2 & 1 & 1 & 1 \\
\hline K6 & 1 & 1 & 1 & 1 & 1 & 2 & 1 & 1 & 1 & 1 \\
\hline K7 & 1 & 1 & 1 & 1 & 1 & 1 & 1 & 1 & 1 & 1 \\
\hline K8 & 1 & 1 & 1 & 1 & 1 & 1 & 1 & 1 & 1 & 1 \\
\hline K9 & 1 & 1 & 1 & 1 & 1 & 1 & 1 & 1 & 1 & 1 \\
\hline K10 & 1 & 1 & 1 & 1 & 1 & 2 & 1 & 1 & 1 & 2 \\
\hline K11 & 1 & 1 & 1 & 1 & 1 & 1 & 1 & 1 & 1 & 1 \\
\hline K12 & 1 & 1 & 1 & 1 & 1 & 1 & 1 & 1 & 1 & 1 \\
\hline
\end{tabular}

TABEL 1 Hasil Kuisioner

Dimana angka 1 merepresentasikan jawaban ya dan angka 2 merepresentasikan jawaban tidak. Dari hasil kuisioner tersebut menghasilkan hasil perhitungan sebagai berikut :

\begin{tabular}{lrrrrrrrrrr}
\hline & P1 & P2 & P3 & P4 & P5 & P6 & P7 & P8 & P9 & P10 \\
\hline Valid & 12 & 12 & 12 & 12 & 12 & 12 & 12 & 12 & 12 & 12 \\
Missing & 0 & 0 & 0 & 0 & 0 & 0 & 0 & 0 & 0 & 0 \\
Mode & 1 & 1 & 1 & 1 & 1 & 1 & 1 & 1 & 1 & 1 \\
Mean & 1 & 1.08 & 1 & 1.08 & 1 & 1.25 & 1.17 & 1.08 & 1.08 & 1.17 \\
Std. & 0 & 0.29 & 0 & 0.29 & 0 & 0.45 & 0.39 & 0.29 & 0.29 & 0.39 \\
$\begin{array}{l}\text { Deviation } \\
\text { Variance }\end{array}$ & 0 & 0.08 & 0 & 0.08 & 0 & 0.21 & 0.15 & 0.08 & 0.08 & 0.15 \\
& & & & & & & & & & \\
\hline
\end{tabular}

TABEL 2 Deskripsi Statistik Hasil kuisioner

Dari hasil tersebut dilihat dari rata-rata jawaban peserta didik cenderung ke arah angka 1 atau bernilai ya. Sehingga dihitung kembali nilai mean atau rata-ratanya untuk melihat hasil secara keseluruhan.

\begin{tabular}{lc}
\hline & Mean \\
\hline Valid & 10 \\
Missing & 0 \\
Mean & 1.092 \\
Std. & 0.083 \\
Deviation & \\
Minimum & 1.000 \\
Maximum & 1.250 \\
\hline
\end{tabular}

TABEL 3 Perhitungan mean secara keseluruhan 
Dengan menghitung secara keseluruhan dapat dilihat mean atau rata-rata dari keseluruhan pertanyaan kuisioner cenderung ke arah 1 atau ya.

\section{KESIMPULAN}

Setelah melakukan pengujian terhadap trivia game yang dibangun dari desain yang diusulkan maka depat dilihat hasil dari keseluruhan jawaban hasil kuisioner adalah 1.092 cenderung ke arah ya, sehingga dapat disimpulkan bahwa game yang dihasilkan dari desain ini memiliki kemampuan memotivasi, menarik dan menyenangkan sehingga desain yang diusulkan dapat digunakan sebagai acuan untuk pembuatan game sejenis.

\section{REFERENSI}

[1] D. C. Rohim, S. Rahmawati, and I. D. Ganestr, "Konsep Asesmen Kompetensi Minimum untuk Meningkatkan Kemampuan Literasi Numerasi Siswa Sekolah Dasar," J. Varidika, vol. 33, no. 1, pp. 54-62, 2021.

[2] Mustagfiroh, "Memanfaatkan Hasil Asesmen Kompetensi Minimum (Akm) Untuk Mendesain Multimodal Learning," Madaris J. Guru Inov., vol. 2, no. 1, 2020.

[3] T. Lim et al., "The LM-GM framework for Serious Games Analysis," Int. J. Serious Games, 2015.

[4] A. D. Gustiana and G. A. Parasaty, "Pengaruh Edu Game Berbasis Komputer Terhadap Peningkatan Kemampuan Aljabar Anak Taman Kanak-Kanak," J. Ilmu Pendidik., vol. 17, no. 3, 2019.

[5] T. K. M. Zali, N. S. Sani, A. H. A. Rahman, and M. Aliff, "Attractiveness Analysis of Quiz Games," Int. J. Adv. Comput. Sci. Appl., vol. 10, no. 8, 2018.

[6] V. Yuenyongviwat and J. Bvonpanttarananon, "Using a Web-Based Quiz Game as a Tool to Summarize Essential Content in Medical School Classes: Retrospective Comparative Study," JMIR Med. Educ., vol. 7, no. 2, 2021.

[7] D. Saputra and A. Rafiqin, "Pembuatan Aplikasi Game Kuis 'Pontianak Punye' Berbasis Android," J. Khatulistiwa Inform., vol. 5, no. 2, 2017.

[8] D. Ardiningsih, "Pengembangan Game Kuis Interaktif Sebagai Instrumen Evaluasi Formatif Pada Mata Kuliah Teori Musik," J. Inov. Teknol. Pendidik., vol. 6, no. 1, 2019.

[9] R. T. Amelia and M. Nuruddin, "Android-Based Quiz Game Development Using Quizizz for Fourth Grade Students at SDN Catak Gayam 1 Mojowarno," IJPSE Indones. J. Prim. Sci. Educ., vol. 2, no. 1, 2021.

[10] I. W. A. Winata, I. N. P. Suwindra, and I. B. P. Mardana, "Pengembangan Quiz Game Fisika Pada Topik Momentum Dan Impuls Untuk Meningkatkan Prestasi Belajar Siswa," JPPF, vol. 8, no. 1, 2018. 